RESOURCE ALLOCATION

\title{
High need patients receiving targeted entitlements: what responsibilities do they have in primary health care?
}

\section{$S$ Buetow}

J Med Ethics 2005;31:304-306. doi: 10.1136/jme.2004.009258

Patient responsibilities in primary health care are controversial and, by comparison, the responsibilities of high need patients are less clear. This paper aims to suggest why high need patients receiving targeted entitlements in primary health care are free to have prima facie special responsibilities; why, given this freedom, these patients morally have special responsibilities; what these responsibilities are, and how publicly funded health systems ought to be able to respond when these remain unmet. It is suggested that the special responsibilities and their place in public policy acquire moral significance as a means to discharge a moral debt, share special knowledge, and produce desirable consequences in regard to personal and collective interests. Special responsibilities magnify ordinary patient responsibilities and require patients not to hesitate regarding attendance for primary health care. Persistent patient disregard of special responsibilities may necessitate limiting the scope of these responsibilities, removing system barriers, or respecifying special rights.

$\mathrm{T}$ he past decade has witnessed a growing tendency to view the patient/clinician relationship as a form of partnership. ${ }^{1}$ Today, in health policy a new emphasis on "partnership" reflects a desire of governments to manage demand for primary healthcare in the face of high public expectations, escalating healthcare costs, and unintended variations in medical practice.

Partnerships confer rights, and arguably reciprocal responsibilities. Most rights, however, are prima facie and may be disputed. A positive account of responsibilities asserts that responsibilities do not depend on the existence of rights. Instead, responsibilities are, in themselves, morally right and mandatory for certain reasons, and predict on balance more positive than negative outcomes for everyone in the long term.

The subject of responsibilities, however, particularly patient responsibilities, is controversial. Scepticism about responsibility involves a normative claim that no agents are ever morally responsible for what they do. In contrast, ordinary morality maintains that people are sometimes responsible for their behaviour, yet the concept of patient responsibilities may still be disputed. It may be "perceived to be paternalistic, a direct threat to patient autonomy and driven by a desire to contain costs". ${ }^{2}$ It may also appear to focus unjustly on one particular lay group, making it unreasonable to use public policy to enforce the responsibilities of certain types of patients.

As a consequence, medical ethics still "dwells on the ethical obligations of doctors to the exclusion of those of patients". ${ }^{3}$ In New Zealand-for example, this ethos continues to underpin government policy and its administration by the government established organisation known as the
Human Rights Commission. Its commissioner acknowledges the existence of patient responsibilities, ${ }^{45}$ but, as part of its current review of the Health and Disability Commissioner Act and the Code of Health and Disability Services Consumers' Rights, he does "not recommend amendment to either the Act or the Code to reflect the rights of providers and responsibilities of consumers". ${ }^{5}$

By comparison, a more concerted and explicit effort has been made internationally to specify and promote patient responsibilities in health care. Statements published by the Department of Health in the United Kingdom, ${ }^{6}$ and professional groups such as the American Medical Association, ${ }^{7}$ exemplify this effort. The internet is replete with the internal statements of healthcare organisations on the responsibilities of their patients, and academic commentators have begun to consider patient responsibilities against a long history of philosophical reflection on moral responsibilities, social justice, and equality.

Arguments for "patient responsibilities" include the following claims: the rights of patients cannot be easily separated from their responsibilities; it is paternalistic for clinicians to "protect" patients from the consequences of their own lay decisions; responsible behaviour by patients contributes to improvements in their own health; the "language of dichotomy used to describe the relationship between clinicians and consumers" ignores the role of patients as coproducers of care $^{8}$; and clinicians may feel unsupported and vulnerable to legislation emphasising patient rights and clinician responsibilities but not clinician rights and patient responsibilities. ${ }^{8}$

For such reasons, patient responsibilities have been suggested to include promotion of self health; respect for others, including behaviour in good faith; appropriate use of health resources in the public sector; sharing of relevant information; serious consideration of offered advice; and adherence to agreed treatment plans. ${ }^{3}$ It has also been suggested that patients are obliged to do what they can to limit the role of clinicians as "captive helpers" (who, as individuals, cannot easily terminate relationships with patients, and who, as a profession, are obliged to provide ongoing care to patients).

\section{RESPONSIBILITIES OF HIGH NEED PATIENTS}

The responsibilities of high need patients in primary health care are not necessarily the same as, and are less clear than, those of other patients. The role and scope of these responsibilities has never been defined, although Anderson-for example," has argued for responsibility criteria for the unemployed. Assuming that patients have responsibilities, and not merely rights, in primary health care, this paper aims to suggest why high need patients receiving state targeted entitlements are free to fulfil special responsibilities in the absence of stronger duties; why, given this freedom, these patients morally have prima facie special responsibilities over and above the responsibilities of other patients; what these 
responsibilities are, and how health systems ought to be able to respond when these responsibilities continue to be unmet. Discussion of these issues has the potential to inform the way in which public policy ought morally to define the role of high need patients in state initiatives to support their use of primary health care.

For the purpose of this analysis, a "patient" is an actual or potential consumer of health care. Patient "responsibility" is defined as an obligation of patients, at minimum not to deny of their own "volition" the rights of others. "Need" is typically defined as capacity to benefit. ${ }^{10}$ For reasons detailed elsewhere, however, ${ }^{11}$ I wish to suggest that for patients to "need" health care, this care must avoid "harm", and these patients must have a right to the care, they must want it and at least some "experts" must believe they ought to be able to access it. ${ }^{11}$ The level of need for care is located in the patient rather than the health state of the patient and is "high" when the foregoing criteria apply most strongly-for example, because of the reasons discussed below for special responsibilities. I will focus on high need patients, as individuals, but some policy initiatives-for example, in New Zealandenable high need patient "groups" (some of whose members have low needs) to access free or low cost primary health care.

\section{SELF AGENCY: A PRECONDITION FOR SPECIAL RESPONSIBILITIES}

Self agency is a precondition of, rather than a reason for, special responsibilities. Critics might argue that high need patients have reduced autonomy and self agency, at least relative to other patients, and so cannot be free to have increased responsibilities. I wish to suggest, however, that high need patients in receipt of targeted entitlements do have such freedom for at least six reasons. Firstly, targeted state support permits these patients to have and meet special responsibilities that would be defined in the context of this support. In New Zealand-for example, state funding arrangements are enabling patients from high need groups to attend primary health care, with reduced or no visit charges $^{12}$; and special responsibilities of these patients would reflect this privileged entitlement. Secondly, such support implies that the state acknowledges the moral capacity of high need patients to use targeted entitlements to good effect. Thirdly, some cultural groups-such as New Zealand Māori, Pacific peoples, and Asians-share an irrevocable, "collective agency" that individual members contribute to, but also benefit from. Fourthly, high need diminishes patient uncertainty regarding when to seek primary health care. Decision making is easier for high need patients than other patients because high need, by definition, means that attendance for this care is never irresponsible. Fifthly, need, as I have defined it, requires the assent of the patients who have it. This predisposes to their acceptance of responsibilities because, other things being equal, patients who acknowledge a need are more likely to accept a responsibility to meet it than are those who do not acknowledge a need. Sixthly, special responsibilities and on balance their desirable consequences (as discussed below) would have the effect of further liberating relatively autonomous high need patients.

\section{REASONS FOR SPECIAL RESPONSIBILITIES}

I now wish to suggest why the ordinary responsibilities of patients are increased prima facie for high need patients eligible for special support from the state. The reasons define ethical imperatives for special responsibilities among these patients and speak to the moral significance of these responsibilities for public policy development in health care. This discussion leads to consideration of how publicly funded health systems ought to be able to respond when high need patients, as partners, continue to default on their responsibilities.

\section{Dischargeable moral debt}

High need patients eligible for targeted state support owe a special moral debt to the state. In any health insurance system, the well subsidise the sick, a disproportionately large number of whom are high need patients. Public financing of targeted entitlements adds to this cross-subsidy and imposes on high need patients a moral debt to compensate, and express gratitude to, the state-for example, through primary health care attendance. This debt is defined by the special entitlements and by future net health costs to the state that would be attributable to current patterns of inappropriate service use by high need patients. This first reason relates special responsibilities to special entitlements whereas the next two reasons do not depend on such rights.

\section{Special knowledge}

All patients hold special knowledge about their own social environment, values, beliefs, and preferences. It is especially important, however, that high need patients share "their" knowledge with clinicians and the health system for two reasons. This knowledge can (a) inform a common understanding of their high need, and thereby (b) reduce the cultural disconnectedness that characterises many clinicians and high need patients. A sharing of special knowledge by high need patients would complement the strategies of clinician/patient pairings based on "deep values"13 or ethnic matching. ${ }^{14}$

\section{Desirable consequences}

These two reasons, namely a dischargeable moral debt and special knowledge, have suggested the moral relevance of special responsibilities independently of their (non-intermediate) consequences. A limitation of these reasons is their dependence on spontaneous moral intuition. Special responsibilities of high need patients, however, and their place in public policy development, also acquire moral significance through their capacity to produce net positive outcomes in the long term, in regard to personal and collective interests.

Supported by targeted entitlements, special responsibilities would weaken the double disadvantage of being a patient and having high need. These responsibilities may be expected to improve the health of high need patients by raising attendance; enabling their participation in healthcare partnerships; and helping clinicians in primary health care to be willing, rather than captive, helpers who would otherwise have to "pick up the pieces". In turn, this care would become a public good for the benefit of all. It would reduce health inequalities; improve population health; potentially avoiding, through preventive care and early disease management of conditions such as angina and asthma, expensive secondary care of illness; and generate other positive benefits for individuals and the state. These include economic benefits for supply and demand and responsible state use of limited public resources for health in order to achieve, in the long term, reductions in welfare and health care expenditures.

\section{FORMS OF SPECIAL RESPONSIBILITIES}

What form should the special responsibilities take? A theme to emerge from the foregoing discussion is that high need patients receiving targeted entitlements have a special responsibility to attend for primary health care. This responsibility includes keeping appointments, and ensuring that clinicians hold correct contact details. Demand management has generally emphasised patients' self care of minor health conditions without recourse to the support of healthcare professionals. Patients have been encouraged to "think 
twice" before seeking medical care. For high need patients, however, the converse appears to be indicated. Their responsibility is not to hesitate regarding attendance to the extent that, among other things, the special entitlements they have been enabled to exercise overcome barriers to attendance. Meanwhile, other, ordinary patient responsibilities are magnified for these high need patients at the clinical level. These responsibilities include a willingness to cooperate with clinicians, as partners, to reach a mutually understood and agreed diagnosis and treatment plan, and then implement it. These responsibilities are not unique to high need patients, but their high needs combined with state support imply an increased personal obligation to meet them.

\section{POLICY RESPONSE TO UNMET SPECIAL RESPONSIBILITIES}

When high need patients do not fulfil their special responsibilities, it is important to investigate why, since publicly funded health systems have a responsibility to address the failure and protect the moral imperatives underpinning the responsibilities. A persistent failure to meet the special responsibilities might be due to system wide problems in and beyond the health sector rather than to the poor intentions of patients. It may be necessary in this situation to remove additional system barriers to patients understanding and meeting their obligations, to limit the scope of these responsibilities, or to do both.

If there is evidence of blameworthiness at the individual patient level, however, it may be appropriate to respecify the allocation of special rights to high need patients. The concept of blame is anathema to some analysts, ${ }^{15}$ but abrogating the accountability of patients who continue to behave irresponsibly condones and reinforces such behaviour. Therefore, I support sanctions that limit particular rights, even where these are tantamount to clinicians withholding health care, although the sanctions must not threaten life or health, must be deserved, and must have a reasonable chance of leading to fulfilment of the responsibilities of high need patients. ${ }^{3}$ In so far as they enforced these responsibilities, the sanctions would help to validate their moral significance and justification. Failure to attempt enforcement would deny public policy an opportunity to protect and advance personal and collective interests in the long term.

Sanctions are consistent with justice because their selective use holds to account patients who have continued to default on the moral debt described above. Sanctions run counter to the intent of targeted funding initiatives to reduce financial barriers to attendance. For sanctions to create a "barrier" to accessing care implies, however, that access would be otherwise unimpeded, and this implication is false because sanctions would arise only when access had already been hindered by an ongoing choice of high need patients to reject access. Moreover, I have already challenged the belief that these patients have reduced relative autonomy that would make special responsibilities unjust.

Indeed, an intention of this paper has been to confront injustice and help further liberate high need patients by outlining an approach that may help to enforce their special responsibilities as partners in health care. These responsibilities are consonant with health needs to which, by definition, these patients have agreed. From my perspective, requiring such assent from individual patients is respectful of their preferences rather than paternalistic; yet, even if need is defined as capacity to benefit, the reasons suggested for special responsibilities still stand. Although this paper has focused on high need patients, the arguments put forward also potentially justify the use of public policy to define and enforce responsibilities of other lay beneficiaries of state support.

Sources of support: This research was made possible by the salary funding provided by ProCare Health Limited.

Correspondence to: S Buetow, Department of General Practice and Primary Health Care, University of Auckland, Private Bag 92019, Auckland, New Zealand; s.buetow@auckland.ac.nz

Accepted for publication 5 July 2004

\section{REFERENCES}

1 McMillan R. Responsibility to or for in the physician/patient relationship. J Med Ethics 1995;21:112-15.

2 Buetow S. The scope for patient involvement in doctor/patient consultations in primary care: the rights, responsibilities, and preferences of patients. J Med Ethics $1998 ; 24: 243-7$ at 244 .

3 Draper H, Sorell T. Patients' responsibilities in medical ethics. Bioethics 2002; 16:335-52 at 336.

4 Patterson R, Van Wyk M. Information management and patients' rights. NZ Fam Physician 2003;30:17-20.

5 Health and Disability Commissioner. A Review of the Health and Disability Commissioner Act 1994 and the Code of Health and Disability Services Consumers' Rights. A resource for public consultation. Wellington: Health and Disability Commission, 2004:25

6 Department of Health. Your guide to the NHS. London: Department of Health, 2001.

7 American Medical Association. E-10.02 patient responsibilities. Chicago: AMA, 2002. http://www.ama-assn.org/ama/pub/category/8325.html (accessed 13 Sept 2004).

8 Health and Disability Commissioner. A Review of the Health and Disability Commissioner Act 1994 and Code of Rights for Consumers of Health and Disability Services. Report to the minister of health, October 1999. Wellington: Disability Services. Report to the minister of health,

9 Anderson ES. What is the point of equality? Ethics 1999;109:287-337.

10 Wright J, Williams R, Wilkinson J. Development and importance of health needs assessment. BMJ 1998;316:1310-13.

11 Buetow S, Coster G. Looking forward to health needs assessments: a new perspective on need. NZ Med J 2001;114:92-4.

12 Ministry of Health. Annual report for the year ended 30 June 2003. Director general's report. Wellington: Ministry of Health, 2003.

13 Veatch R. Abandoning informed consent. Hastings Cent Rep 1995;25:5-12.

14 Ziguras S, Klimidis S, Lewis J, et al. Ethnic matching of clients and clinicians and use of mental health services by ethnic minority clients. Psychiatr Serv 2003:54:535-41.

15 Berwick D. Continuous improvement as an ideal in health care. N Eng J Med 1989;320:53-6. 